\title{
Psychotherapies should be assessed for both benefit and harm ${ }^{\dagger}$
}

Jan Scott and Allan H. Young

\section{Summary}

The past four decades have witnessed a transformation in research on the benefits of psychological therapies.

However, even though therapists highlight that negative and adverse effects are seen in day-to-day practice, research on the negative effects of psychotherapy is insufficient. Given the unrelenting popularity of therapies, the argument for examining the adverse effects of psychotherapy would seem to be compelling. Such a strategy would extend beyond supervision of individual therapists to the introduction of monitoring systems that allow for a more systematic examination of failed psychotherapy interventions (such as exist for medication prescribing). The starting point could be the development of a consensus on how to define, classify and assess psychotherapy side-effects, unwanted events, adverse reactions, etc. This would provide a conceptual framework for communication, monitoring and research. This approach should not be viewed as an attack on therapies: every branch of medicine learns from mistakes, the same must surely be true for psychological treatments.

\section{Declaration of interest}

J.S. has undertaken research on the use of psychological interventions, especially cognitive-behavioural therapy (CBT) either alone or in combination with medications, for common and for severe mental disorders. She is a Distinguished Founding Fellow of the Academy of Cognitive Therapy and has contributed to several committees examining psychotherapy practice, such as the recent proposals on supervision competencies for psychotherapists (see www.ucl.ac.uk/CORE). A.H.Y has received payment for lectures and advisory boards for all major pharmaceutical companies with drugs used in affective and related disorders

\section{Copyright and usage}

(C) The Royal College of Psychiatrists 2016.
Jan Scott (pictured) is Professor of Psychological Medicine at Newcastle University, UK, and Visiting Professor at the Centre for Affective Disorders, Institute of Psychiatry, Psychology \& Neuroscience, UK; Norwegian University of Science and Technology, Trondheim, Norway; and The University of Sydney, Australia. Allan H. Young holds the Chair of Mood Disorders and is Director of the Centre for Affective Disorders in the Department of Psychological Medicine, Institute of Psychiatry, Psychology and Neurosciences at King's College London, UK.

Over the past 40 years, enormous progress has been made in psychotherapy research and there have been repeated demonstrations of positive effects for a range of psychological interventions, especially in the treatment of depression and anxiety disorders. ${ }^{1,2}$ However, the study of adverse effects has not received the same level of attention. ${ }^{3}$ This is despite the fact that even the earliest metaanalyses identified that, of nearly 500 outcomes studied, about $10 \%$ of the effect sizes were negative. ${ }^{4,5}$ Therapists highlight that negative or adverse effects are seen in day-to-day practice; ${ }^{6,7}$ thus the case for systematically examining the adverse effects of psychotherapy would seem to be compelling.

It is unsurprising that psychotherapy can have negative outcomes; indeed, it simply indicates that psychological treatments are similar to almost every other therapeutic intervention used in medicine or mental health, from aspirin to brain surgery. ${ }^{8}$ However, what sets psychotherapies apart is that they are frequently recommended as the treatment of choice for a wide variety of patients, and often in preference to medications, because of the presumption that therapy will be helpful to all patients, or at the very least will not have any adverse effects. ${ }^{7,8}$ This is in marked contrast to prevailing social and media representations of psychotropic medications. ${ }^{7}$

${ }^{\dagger}$ See pp. 210-212 and 260-265, this issue.
One reason for the relative lack of scrutiny of therapies and the rigorous scrutiny of medications is the values that are brought to bear by three 'interested parties': society, the individual, and health professionals ${ }^{9}$. Increasingly, publications used to inform patient choice on available interventions for common mental disorders suggest that therapies and medications are equally efficacious, but that medications have side-effects, adverse effects or are addictive, whereas psychotherapy is nearly always portrayed with the absence of such issues. ${ }^{7}$

Negative perceptions of medications are probably increased by regulatory requirements to identify drug harms as well as benefits in any scientific communications, and this feeds into the view that they are dangerous. The US Food and Drug Administration (FDA) requires side-effects or adverse effects to be listed alongside the benefits of a drug, and the UK regulators who undertake post- marketing surveillance of medications (the Committee on Safety of Medicines) amended the 'yellow card' scheme for reporting adverse effects of drugs, so that patients have been able to use them since about $2004 .^{7}$ Although these strategies are entirely reasonable, no such systems or requirements are in place for therapies. ${ }^{3,7}$

One problem in trying to examine the issues of negative effects of psychological therapy is that the research approaches that are suitable for identifying positive effects often obscure negative effects, ${ }^{3,10,11}$ an issue that is compounded by the lack of a theoretical concept on how to define, classify and assess psychotherapy sideeffects. $^{10,11}$ This does not mean that therapy researchers are complacent or negligent and indeed when problems have been identified changes in clinical practice have been instigated. One of the best examples is the transformation in perception of 'critical incident stress debriefing' (CISD), which was used routinely to help people immediately after a traumatic event. Over time it became apparent that significant subgroups of people who were treated with CISD actually experienced deterioration rather than an improvement in their psychological well-being, leading 
to changes in clinical guideline recommendations. ${ }^{12}$ However, in the absence of empirical predictors of likely adverse effects of therapy, placing a greater emphasis on clinical monitoring may provide a means to better understand the causes of negative or iatrogenic effects and to differentiate them from lack of therapeutic efficacy or from short-lived (but distressing) therapy side-effects. ${ }^{3}$

In the paper by Crawford et al, ${ }^{13}$ about 1 in 20 adults offered therapies via the National Health Service or Improving Access to Psychological Therapies reported negative effects. Younger adults, individuals from minority ethnic groups (especially from Black, Asian and Chinese populations) and 'non-heterosexuals' (from lesbian, gay, bisexual, trans-sexual and transgender populations) were up to three times more likely to report negative effects than other individuals; unfortunately, other characteristics that can predict negative experiences, such as education and income, ${ }^{14}$ were not examined. In terms of types of therapy, self-reported rates of negative effects ranged from $4 \%$ for cognitive-behavioural therapy to $9 \%$ for psychodynamic therapy. Number of therapy sessions did not predict negative effects, but insufficient information about the nature of the therapy or rationale for the interventions was associated with negative experiences of therapy.

Crawford and colleagues go to some lengths to differentiate negative effects from side-effects or lack of efficacy, but the survey did not examine whether any therapist characteristics contributed to the patients' negative experiences of therapy. For example, it is known that therapeutic alliance consistently predicts satisfaction with the relationship and with clinical outcome, and also that patients who report negative effects are often seen by therapists who are slow to recognise the severity of the patients' disturbance and their magnitude of need. ${ }^{15}$ This is important, as it is clear that expertise (i.e. clinical skilfulness in delivering the therapy) rather than experience (years of practicing a therapy) can make a critical difference to a patient's experience. ${ }^{16}$ Also, several studies highlight that the general competence of a therapist is not synonymous with either their cultural competence ${ }^{17,18}$ or level of comfort in discussing sexuality. ${ }^{19,20}$

\section{Conclusions}

Empirical research on the negative effects of psychotherapy is insufficient, partly because there is a lack of a coherent framework for defining, discussing and monitoring issues such as unwanted events, adverse reactions, malpractice reactions or deterioration of illness. ${ }^{11}$ However, given the unrelenting popularity of therapies as a treatment for common mental disorders in primary and secondary care, it is important to develop a strategy for examining failed psychotherapy interventions. ${ }^{3,8}$ This is not an attempt to undermine therapies, but is likely to be beneficial. First, because it is likely to lead to improvements in techniques and practice, ${ }^{3,8}$ and second, because every branch of medicine learns from its mistakes; ${ }^{9,10}$ it is inconceivable that the same is not true for psychotherapies.
Jan Scott, MB, BS, MD, FRCPsych, Department of Academic Psychiatry, Institute of Neuroscience, Newcastle University, UK; Allan H. Young, MB, ChB, MPhil, PhD, FRCPsych, FRCP (C), Centre for Affective Disorders, Department of Psychological Medicine, Institute of Psychiatry, Psychology and Neurosciences, King's College London, UK

Correspondence: Professor Jan Scott, Academic Psychiatry, Wolfson Unit, Campus for Vitality \& Ageing, Westgate Road, Newcastle upon Tyne NE4 6BE, UK. Email: jan.scott@newcastle.ac.uk

First received 19 Oct 2015, accepted 8 Dec 2015

\section{References}

1 Cuijpers P, Sijbrandij M, Koole S, Huibers M, Berking M, Andersson G. Psychological treatment of generalized anxiety disorder: a meta-analysis. Clin Psychol Rev 2014; 34: 130-40.

2 Clarke K, Mayo-Wilson E, Kenny J, Pilling S. Can non-pharmacological interventions prevent relapse in adults who have recovered from depression? A systematic review and meta-analysis of randomised controlled trials. Clin Psychol Rev 2015; 39: 58-70.

3 Barlow DH. Negative effects from psychological treatments. Am Psychol 2010; 65: 13-9.

4 Smith ML, Glass GV, Miller TI. The Benefits of Psychotherapy. Johns Hopkins University Press, 1980.

5 Shapiro DA, Shapiro D. Meta-analysis of comparative therapy outcome studies: a replication and refinement. Psychol Bull 1982; 92: 581-604.

6 Castonguay L, Boswell J, Constantino M, Goldfried M, Hill C. Training implications of harmful effects of psychological treatments. Am Psychol 2010; 65: 34-49.

7 Nutt DJ, Sharpe M. Uncritical positive regard? Issues in the efficacy and safety of psychotherapy. J Psychopharmacol 2008; 22: 3-6.

8 Mohr DC. Negative outcome in psychotherapy: a critical review. Clin Psychol Sci Pract 1995; 2: 1-27.

9 Strupp H, Hadley S. A tripartite model of mental health and therapeutic outcomes: with special reference to negative effects in psychotherapy. Am Psychol 1977; 32: 187-96.

10 Dimidjian S, Hollon S. How would we know if psychotherapy were harmful? Am Psychol 2010; 65: 21-33.

11 Linden M. How to define, find and classify side effects in psychotherapy: from unwanted events to adverse treatment reactions. Clin Psychol Psychother 2012; 20: 286-96.

12 Lilienfeld S. Psychological treatments that cause harm. Perspect Psychol Sci 2007; 2: 53-70.

13 Crawford MJ, Thana L, Farquharson L, Palmer L, Hancock E, Bassett $P$, et al. Patient experience of negative effects of psychological treatment: results of a national survey. Br J Psychiatry 2016; 208: 260-5.

14 Lambert MJ, Barley DE. Research summary on the therapeutic relationship and psychotherapy outcome. Psychotherapy 2001; 38: 357-61.

15 Scott J. Cognitive-behavioural therapy for severe mental disorders: back to the future? Br J Psychiatry 2008; 192: 401-3.

16 Imel ZE, Baldwin S, Atkins DC, Owen J, Baardseth T, Wampold BE. Racial/ethnic disparities in therapist effectiveness: a conceptualization and initial study of cultural competence. J Couns Psychol 2011; 58: 290-8.

17 Owen J, Drinane J, Tao KW, Adelson JL, Hook JN, Davis D, et al. Racial/ethnic disparities in client unilateral termination: the role of therapists' cultural comfort. Psychother Res 2015; 21: 1-10.

18 Campos PE, Goldfried MR. Introduction: perspectives on therapy with gay, lesbian, and bisexual clients. J Clin Psychol 2001; 57: 609-13.

19 Harris SM, Hays KW. Family therapist comfort with and willingness to discuss client sexuality. J Marital Fam Ther 2008; 34: 239-50.

20 McHugh RK, Whitton SW, Peckham AD, Welge JA, Otto MW. Patient preference for psychological vs pharmacologic treatment of psychiatric disorders: a meta-analytic review. J Clin Psychiatry 2013; 74: 595-602. 